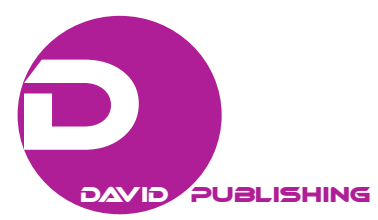

\title{
Trends in Corporate Social Responsibility Among Public Service Media in Europe
}

\author{
Tania Fernández-Lombao, Andrea Valencia-Bermúdez, Francisco Campos-Freire \\ University of Santiago de Compostela, Santiago, Spain
}

\begin{abstract}
Corporate Social Responsibility (CSR) is the voluntary commitment taken over by companies in social, economic, and environmental terms. The aim is to counteract impacts generated by their activity. While the concept is genuinely linked to the private sector, this self-regulated system has been steadily introduced in some European public service media. Indeed, CSR is one of the mechanisms to face the challenges of the sector, both the financial crisis and the lack of trust. Seven public service media from the European Union are reporting-via their websites-on their CSR strategies. Annual reports on their performance are issued by the German ZDF, the Spanish RTVE, the Portuguese RTP, the British BBC, the Irish RTÉ, the Finnish YLE, and the Italian RAI. Also, four other corporations_-VRT and RTBF from Belgium, FT from France, and DR from Denmark include a section on corporate social responsibility on their annual reports. The aim of this paper is to know which of the trends in CSR are dominant among public service media in Europe, namely economy, environment, and society. The content analysis of corporate reports is the method used for the research.
\end{abstract}

Keywords: corporate social responsibility, public service media, accountability, European Union

\section{Literature Review}

The first great economic crisis of the present century has rocked again the foundations of public service media. When trust and reputation fail as values, organizations duplicate efforts to renew and protect them. However, for that to happen, they need to transform their practices and renew their corporate culture, i.e. make things right.

Shouldering that social responsibility is the link in the value chain which is being linked to reputation. The interest in CSR has been endlessly increasing since the economic crisis. In fact, conflicts and indicators are thus reflected in European communication companies (Campos, 2012).

This self-regulation system is supported by five elements listed by Zoellick (2009): 1) responsible globalization, in which inclusion and sustainability are above the enrichment of a few; 2) environmental

Acknowledgements: This work is elaborated within the framework of the program of activities of the Network XESCOM (REDES 2016 GI-1641 XESCOM), of the Department of Culture, Education and University Management of the Xunta de Galicia, with reference ED341D R2016/019. It is part of the R+D research project CSO2015-66543-P, belonging to the National Programme for Encouraging Excellent Scientific and Technical Research, national subprogram of knowledge creation from the Spanish Ministry of Economy and Competitiveness, entitled "Indicators related to broadcasters' governance, funding, accountability, innovation, quality, and public service applicable to Spain in the digital context”.

Tania Fernández-Lombao, associate professor, University of Santiago de Compostela, Santiago, Spain.

Andrea Valencia-Bermúdez, Ph.D. candidate, University of Santiago de Compostela, Santiago, Spain.

Francisco Campos-Freire, professor, University of Santiago de Compostela, Santiago, Spain.

Correspondence concerning this article should be addressed to Tania Fernández-Lombao, Os Castros, 13. Castro Ribeiras de Lea. Castro de Rei 27260, Lugo. 
management; 3) financial responsibility, both at personal and systemic level; 4) multilateralism, in which countries and institutions are looking for real solutions to complex and inter-connected problems; and 5) responsible actors, with obligations and benefits.

Corporate social responsibility consists of establishing relationships between companies and their stakeholders, from the staff and shareholders to the civil society and the environment. The ultimate goal is to understand their concerns and offer solutions.

As it is widely assumed that the incorporation of stakeholders in the strategic management of companies has a positive impact (Husted \& Allen, 2001), distinguishing approaches should be implemented. These strategies should include the demands of the targeted groups, the search for synergies between R\&D, and the design of social projects (Toro, 2006).

Based on the principles of CSR, organizations make efforts to improve their social environment (Frederick, 1978; Sethi, 1975; Carroll, 1993); to act responsibly; and to be guided by fundamental ethical values towards society (Holme \& Watts, 2000).

Social responsibility is linked to the concept of transparency. Transparency is the space in which companies and their stakeholders coexist, as well as the place where trust is generated. Media outlets have made possible to the expansion of transparency as a practice, but they should not scape from it when it comes to their own business strategy.

The condition of public service media as companies offering a product or service to society forces them to meet certain criteria: management, organization, and accountability as the rest of organizations. Also, their activity highlights their responsibility towards citizenry (López Cepeda \& Manfredi, 2013).

Performance reports have been elected by public service media as the main mechanism to face the challenge of corporate social responsibility. Most of them are published annually.

Voluntary communication is part of the socially responsible behavior assumed by companies (Pava \& Krausz, 1997). Indeed, the most committed companies have the highest data quality for their stakeholders (Gelb \& Strawser, 2001).

\section{Sample and Method}

The paper aims at determining the agreements and divergences among public service media in Europe as regards corporate social responsibility strategies. For this purpose, our attempt is to understand the development of CSR strategies in public broadcasters in order to address the needs of their stakeholders.

The literature on CSR often refers to the triple statement to value the level of commitment assumed by organizations from three points of view: economy, environment, and the social sector. These three blocks maintain this communication that attempts to shed light on public service media's agendas.

The first part of the research has insisted on checking whether or not public service media have introduced CSR as a self-regulation mechanism. The exercise has shown that only seven of them are reporting on this topic: the German ZDF, the Spanish RTVE, the Portuguese RTP, the British BBC, the Irish RTÉ, the Finnish YLE, and the Italian RAI. Also, four other corporations-VRT and RTBF from Belgium, FT from France, and DR from Denmark include a section on corporate social responsibility on their annual reports.

The seven above-mentioned public service media are the sample representing the sample of this research. The reason why the remaining four are not included is the absence of specific CSR documents, which make it difficult to gather the necessary information on this issue and to make valid comparisons between organizations. 
The second phase of explorations of the content analysis of the last seven reports on CSR, is issued by the seven above-mentioned companies. The main goal is to collect the required information to identify the cornerstone of their CSR strategy: economy, environment, and society.

\section{Results and Discussion}

In the context of loss of credibility and reputation of European public service media, CSR provides a solution to regain ethics and accountability to the increasingly active stakeholders, as well as to reformulate the public service remit.

The CSR strategy in the ZDF revolves around three pillars: the social commitment, the cooperation in the media industry and the staff. Also, the German broadcaster reports biannually on its performance in corporate social responsibility through its website. The last report was issued in 2013-2014.

When it comes to social commitment, the ZDF highlights the universality of its services, with a wide choice for people with visual and hearing disabilities (subtitles and audio description). Also, this section includes their financial commitment to research on diseases and groups at risk of social exclusion. As regards the staff, it bets on work flexibility, which is solved with a rate of 25 percent of part-time employees. These measures help reconcile work and family life.

The ZDF has also taken a commitment to develop an open standard, which regulates the coexistence of linear and non-linear services through the hybrid television (HbbTV). Also, the German broadcaster is funding body of the European cinema, as laid down in its strategy.

Corporate social responsibility in RTVE is based on the 10 principles established by the UN Global Compact, which fall into four large areas: human rights, labor standards, environment, and anti-corruption. In August 2016, RTVE has already published three progress reports, covering the period from 2012 to 2014.

In the social field, the Spanish corporation has signed specific agreements with 31 non-profit organizations, including the SGAE, the ONCE and various universities, apart from other 26 public institutions. The Spanish broadcasters also foster volunteerism, which integrates its staff, who, on a voluntary basis, to help vulnerable groups. The staff chapter highlights the Equality Plan (2012) to guarantee representativeness, to remove all sexist language, and to promote the presence of women in management positions.

When it comes to transparency and good governance, RTVE presents the main economic results, including the account balance. It also includes the emergence of multi-platforms and multiscreen, with the redesign of the website, the diversification of HbbTV contents for connected televisions (red button and second-screen experiences). The last report barely mentions the environmental section.

The Finnish YLE distinguishes responsibility in contents, the care for the environment and the financial management as the main pillars of corporate social responsibility. The last annual report corresponds to corporate year 2015.

The strategy is linked to the public service remit with regard to the defense of the freedom of expression, pluralism and universality, with the offer of sign language services, audio-description, subtitles and various languages (Finnish, Swedish, Russian, and English). Among the social actions undertaken, there are projects to fight against alcoholism, to promote communication skills in schools, and to support charitable organizations.

As regards environment, it outlines the intention to reduce the facilities by up to 40 percent in 2020 in order to use more efficiently the space and improve the energy performance. At the end of 2016, YLE set three objectives: to reduce the consumption of electricity in its headquarters by up to 15 percent; to increase the use 
of hybrid vehicles; and to reduce the emissions per driven kilometer; and to maintain the mixing of waste below 10 percent. The third pillar of YLE's strategy, related to financial management, bets on transparency and reports on annual economic results.

The Irish RTÉ published between 2006 and 2009 a specific report on corporate social responsibility, which did not continue from then on. Nevertheless, it is still developing strategy in the field. For instance, the RTÉ issued a report on environmental performance for the period 2003-2013.

In 2012, the Irish broadcaster decided to review its environmental performance. Thus, it implemented a plan using developed indicators. Also, the RTÉ launched assessments systems for its performance through the improvement of the Albert reference mechanism, developed by the British Academy of Cinema and Television. The tool was also used by the BBC to measure the carbon footprint, as well as to seek agreements with other organizations, as the European Broadcasting Union.

The RAI reports on their social responsibility performance through its Social Balance. The last one dates from 2014 and summarizes a ten-axes strategy. Apart from a space on its remit, the RAI reports on financial information, its economic resources and accounting segregation. The broadcaster also draws attention to ethics and transparency and, in consequence, it is committed to reporting on its daily performance to its stakeholders, to carry out audits, and to monitor corporate profiles on social networks. This section includes efforts for the technological renovation and the digital offer.

As far as social issues, the RAI is focused on the offer for people with disabilities. Hours of contents with subtitles, audio-description and sign language. Also, the broadcaster has a social progress report on the website. As far as human resources, the Social Balance makes the case for equal opportunities among the staff and details all its types of contracts in force.

Since 2010, the Portuguese RTP has published annually a sustainability report, albeit the last one is from 2014. Governance is the most notable element, while innovation and digital services are also mentioned in the same section.

The social section presents the work of the project RTP+ to support solidarity actions. The RTP+ is usually associated with projects developed by other institutions, helping to disseminate their complaints. The environmental strategy is based on the results of its policies and actions to reduce the consumption of paper, water, the total fleet of vehicles, and the production of greenhouse gases.

CSR reports of the BBC have two main sections: society and environment. Concerning the first one, the British corporation supports universality of services; includes the improvement of digital features, especially the BBC iPlayer; guarantees the access, with subtitles for the whole offer; and increases the use of audio-description and sign language.

As regards external social actions, the BBC organizes marathons for fund-raising; the launch of radio programs in countries dealing with complex emergencies; the partnership with charitable organizations and foundations; the promotion of concerts; and the launch of programs for attracting talent. In the environmental sector, the BBC operates on four levels: the reduction of water costs; the improvement of recycling ratios; the reduction of carbon emissions using the tool Albert; and the substitution of physical travel with applications like videoconferencing and virtual collaboration tools.

\section{Conclusions}

The trends in corporate social responsibility are widely identified in scientific literature. Nevertheless, 
each organization decides its own itinerary to meet the expectations of stakeholders. In any case, the ultimate aim is to increase credibility and trust and, consequently, economic profitability.

When it comes to public service media, the main goal is not so much the economic profitability (as they receive public funds or licence fees), but the audience share, which, by now, is the most reliable indicators to assess PSM's credibility.

Corporate social responsibility has had a strong impact on public companies, as it helps them to reinforce their public service remit. Nevertheless, CSR contains voluntary actions beyond those established by regulation, and that is what public service media in Europe are working on.

The first conclusion to be drawn from this research is that social issues are the priority for public service media in Europe, even above the commitment to in-house production of services and news content.

Table 1

Trends in Corporate Social Responsibility Among PSM in Europe

\begin{tabular}{lll}
\hline Corporation & First priority & Second priority \\
\hline ZDF-Germany & Social & Media industry \\
RTVE-Spain & Social & Good governance and finance \\
YLE-Finland & Environmental & Social \\
RTÉ-Ireland & Environmental & - \\
RAI-Italy & Social & Good governance \\
RTP-Portugal & Good governance and finance & Social \\
BBC-United Kingdom & Social & Environmental \\
\hline
\end{tabular}

Source: Prepared by authors (2016).

Four of the seven analyzed broadcasters give priority to social issue, and two of the remaining three place it in second place. The RTÉ is excluded from this analysis, as the last report was only focused on environment.

The environment represents the most important issue for the Finnish YLE and the Irish RTÉ. The English $\mathrm{BBC}$ establishes it as the second priority. It can be then concluded that public service media in Europe place environment as the second priority.

Good governance and finance are highlighted by the Portuguese RTP, while the Spanish RTVE and the Italian RAI place it in a second positions. Despite the importance of transparency and accountability towards stakeholders, they do not have a presence on CSR reports. It should be noted, however, that these corporations have specific annual reports on economic performance.

Analyzed corporations still face strong resistance to integrated reports, that is to say, those that combine economic performance with social and environmental issues. This way of reporting is used by worldwide companies, on the recommendation of international organizations as the Global Reporting Initiative. The RTP is the only one that publishes an integrated report, combining almost equally economic, social, and environmental information.

\section{References}

Campos, F. (2012). Los principales grupos mediáticos europeos aumentan su interés por la Responsabilidad Social Corporativa. III Conference of the Spanish Association for Communication Research “Communication and Risk”. January 19, 2012 (Tarragona, Spain).

Carroll, A. (1993). Business and society: Ethics and stakeholder management. Cincinnati: South-Western Publishing. Frederick, W. C. (1978). From CSR1 to CSR2: The maturing of business-and-society thought. Business and Society, 33(2), 150-164. 
Holme, L., \& Watts, P. (2000). Corporate social responsibility: Making good business sense. Switzerland: World Business Council for Business Development.

Husted, B. W., \& Allen, D. B. (2001). Toward a model of corporate social strategy formulation. Proceedings of the Social Issues in Management Division at Academy of Management Conference. Washington D.C.

Gelb, D. S., \& Strawser, J. A. (2001). Corporate social responsibility and financial disclosures: An alternative explanation for increased disclosure. Journal of Business Ethics, 33(1), 1-13.

López Cepeda, A., \& Manfredi, J. L. (2013). Análisis de la transparencia de las páginas web de los principales medios de comunicación audiovisuales en España. Trípodos, 32, 45-61.

Pava, M. L., \& Krausz, J. (1997). Criteria for evaluating the legitimacy of corporate social responsibility. Journal of Business Ethics, 16(3), 337-347.

Sethi, S. P. (1975). Dimensions of corporate social responsibility. California Management Review, 17(3), 58-64.

Toro, D. (2006). El enfoque estratégico de la responsabilidad social corporativa: Revisión de la literatura académica. Intangible Capital, 14(2), 338-358.

Zoellick, R. (2009). La era de la responsabilidad. Madrid: Diario El País. 